\title{
Getting More out of Storm Surge Forecasts: Emergency Support Personnel Needs in North Carolina ${ }^{0}$
}

\author{
ROBERT MUNROE \\ NOAA/National Weather Service, Los Angeles/Oxnard Weather Forecast Office, Oxnard, California, and Department of Geography, \\ Planning, and Environment, East Carolina University, Greenville, North Carolina \\ BURRELL MONTZ AND SCOTT CURTIS \\ Department of Geography, Planning, and Environment, East Carolina University, Greenville, North Carolina
}

(Manuscript received 13 July 2017, in final form 28 May 2018)

\begin{abstract}
Storm surge has been identified as a dangerous and damaging coastal hazard that is expected to be exacerbated by rising sea levels. However, storm surge research and applications are relatively new and poorly understood compared to other storm-related hazards. This survey-based research of emergency support personnel across eastern North Carolina aims to connect ongoing research with the needs of storm surge users. Results indicate that emergency managers and other emergency support functions depend on storm surge information to assess and communicate risk, to educate the public, to evacuate the public, or for longterm resilience and recovery planning. They were generally satisfied with the type and timing of currently available surge information, but desired additional types of surge information (i.e., timing) and longer lead times.
\end{abstract}

\section{Introduction}

Storm surge has been identified as the leading cause of death from tropical cyclones (Rappaport 2014) but is relatively poorly understood compared to its counterparts (i.e., wind) in tropical and extratropical cyclones. Increased emphasis on the storm surge hazard continues within the research community and the federal government, particularly the National Hurricane Center (NHC) and the National Weather Service (NWS) as evidenced by the ongoing research and development of storm surge products and services (e.g., Morrow et al. 2015; NOAA 2017). A significant portion of this push to better understand storm surge hazards has been focused on how the public and state and local government officials, including emergency managers, currently use storm surge information and how the NHC and NWS can better

Supplemental information related to this paper is available at the Journals Online website: https://doi.org/10.1175/WCAS-D-170074.s1.

Corresponding author: Robert Munroe, robert.munroe@noaa. gov cater to these user groups' needs (Losego et al. 2012; Morrow et al. 2015). Some of this research was performed to assist in implementing storm surge watch and warning products that became operational for the 2017 Atlantic hurricane season (NOAA 2017). These studies provided valuable feedback about how surge information is currently used and how changes in wording and graphics of the experimental surge products are likely to improve user response to this hazard. One of the major findings of this work is that surge information is poorly understood, especially for members of the public (Lazo and Morrow 2013; Meyer et al. 2014; Morrow et al. 2015; Carr et al. 2016).

Different audiences have varying needs, interpretations, and uses of hazard-related information, and their decisions depend on how they understand the information that is available to them (Morss et al. 2010). The literature is ripe with studies that address both what information people use as well as how they use (or do not use) information to make decisions when faced with an impending event [see Dillon et al. (2011), Wood et al. (2012), and Bradford et al. (2012) for examples]. While there is some concern that uncertainty in forecasts may be difficult for individuals to understand (Demeritt et al. 2010), 
emergency managers and other emergency support professionals address uncertainty everyday as they prepare for severe weather. Hoekstra and Montz (2017a) showed how Lindell and Perry (2012)'s Protective Action Decision Model (PADM) can be applied to emergency management decision-making because it incorporates the predecision stage that includes perceptions of the threat, protective actions, and stakeholders. Yet, all of this is dependent on the availability of information that links science to decision-making at both spatial and temporal scales that fit the context in which decisions are being made (Morss et al. 2011).

User feedback has been instrumental to implementing and advancing storm surge products and related use of storm surge information by the public (e.g., Lazo and Morrow 2013), emergency managers (EMs), and other emergency support functions (ESFs). In fact, the direct use of these studies "to empirically elicit stakeholder input as part of product development" was seen as a unique endeavor within the National Oceanic and Atmospheric Administration (NOAA) (Morrow et al. 2015, p. 44). This research takes a similar approach by eliciting user input to help inform the potential development of surge products. In contrast to previous work, this study turns its focus toward surge lead times beyond several days as well as the types of surge information beyond surge height and timing. Further, it takes advantage of an Integrated Warning Team meeting to administer the survey, thereby focusing on professionals who are 1) more comfortable with longer lead times and the uncertainties that accompany them and 2) more likely to use the information in their decision-making.

A growing body of research has shown that simplified or less detailed storm surge information may be attainable beyond current storm surge numerical models to the weekly, monthly, and seasonal time scales, due to both improvements in weather and climate predictability as well as increasing understanding of storm surge (Dolan and Davis 1994; Zhang et al. 2000; Wakelin et al. 2003; DeGaetano 2008; Sweet and Zervas 2011; Dangendorf et al. 2012; Thompson et al. 2013; Munroe and Curtis 2017; Catalano and Broccoli 2018). In an earlier study, Munroe and Curtis (2017) defined several surge shape parameters, including height, power, duration, skewness, and kurtosis, and found significant relationships between this information and climate variables (i.e., El Niño-Southern Oscillation) for the northern Outer Banks of North Carolina. While theoretically surge information at longer lead times could be highly beneficial to those who use storm surge information in decisionmaking, the impact this information could have for surge-related decision-making is not fully understood. There is a range of users of such information with a range of needs. For instance, EMs and ESFs may find long-range surge forecasts to be helpful in their operations for, among other things, estimating potential resource needs. Thus, this follow-up research aims to assist in bringing the growing body of storm surge research to operations through the following objectives: by documenting 1) what storm surge information is currently used by EMs and other ESFs, 2) what lead times are currently useful, and 3) what additional surge information, lead times, and related products could add further value for their operations. It is anticipated that the results of this research will foster understanding of how the development of additional surge products at different temporal scales might complement those at shorter lead times to benefit users of storm surge information. A recommendation of how to incorporate the findings of this study into operations through additional surge products follows at the end of the summary and conclusions section.

\section{Study area}

The region on which this study focuses is the NWS Newport/Morehead City Weather Forecast Office (WFO) County Warning Area (CWA) comprising 15 counties (Fig. 1). Eight of those counties are adjacent to the Atlantic Ocean and/or Pamlico-Albemarle Sounds and are susceptible to storm surge nearly year round. One strength of the selected study area is that it frequently experiences storm surge, significant at times, from both tropical and extratropical cyclones. In fact, from a research perspective, it may be the most optimal location in all of the continental United States in terms of experiencing storm surge from both storm types. This is significant because storm surge characteristics and related impacts can differ significantly between the two storm types and also generally occur during different seasons (e.g., Munroe and Curtis 2017). As a result, EMs, ESFs, other officials, local residents, and even tourists can be affected or respond differently to surge events from the two storm types. Tropical cyclone storm surge is most common during the Atlantic basin hurricane season from June through November and extratropical cyclone surge is most common from October through April or May (Dolan and Davis 1994; Zhang et al. 2000; Sweet and Zervas 2011; Thompson et al. 2013; Munroe and Curtis 2017). A second strength, but also limitation, of this study is that it is regionally specific, focused across eastern North Carolina. For example, barrier island systems such as the Outer Banks of North Carolina often have a limited number of evacuation routes, which typically results in longer evacuation times than other coastal areas connected more directly 


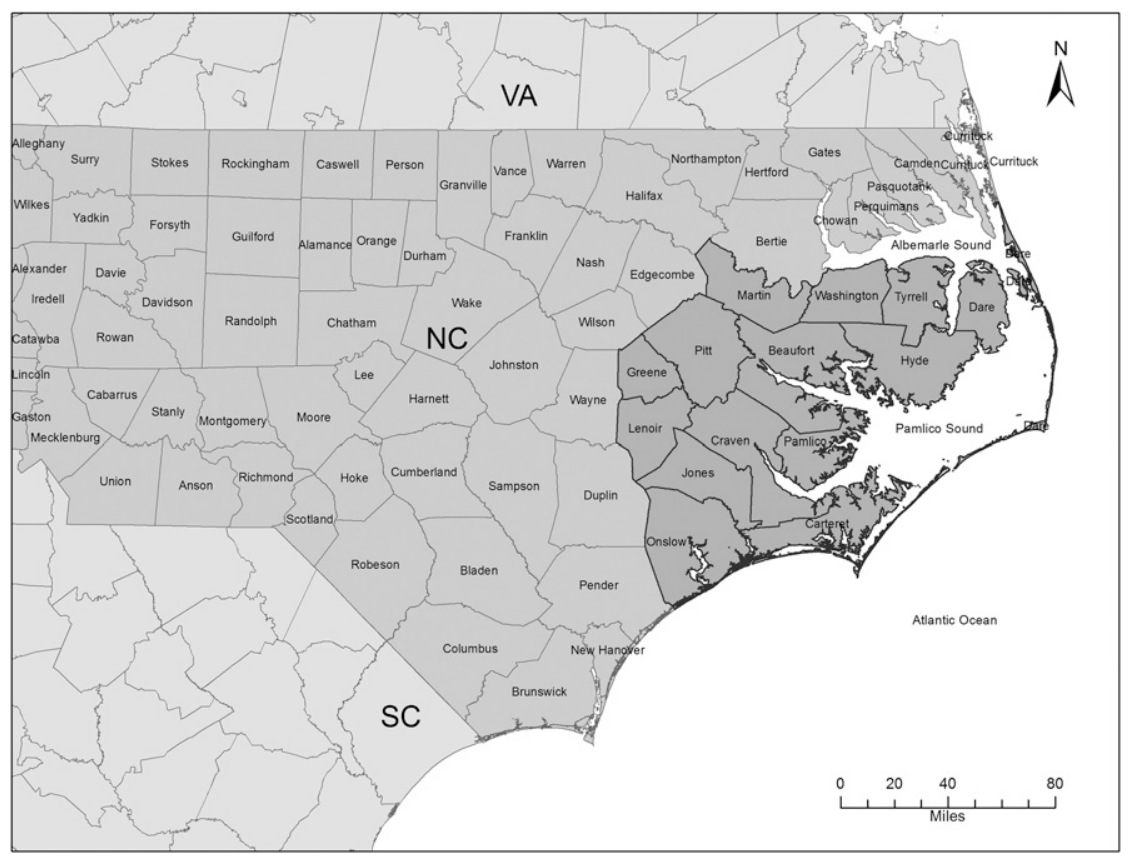

FIG. 1. Study area displaying NWS Newport/Morehead City WFO CWA in eastern North Carolina, denoted by the darkest gray shading.

with the mainland. On one hand, this speaks to the importance of longer lead times for surge. On the other hand, coastal areas without significant constraints to evacuation times may have different needs in terms of storm surge lead times and preferred types of surge information. Nonetheless, the lead times that the research reported here addresses may still be of use in such areas to understand possible future events and consider needed resources. Therefore, it may be beneficial to undertake similar studies for other regions of differing coastal characteristics.

\section{Methods}

A 22-question mixed multiple-choice and free-response survey was developed to address the research objectives (see online supplemental material for survey). The survey was administered by the first author in June 2016 at the Beaufort Hurricane Conference and Integrated Warning Team (IWT) meeting hosted by the NWS Newport/ Morehead City WFO at the NOAA Beaufort Laboratory in Beaufort, North Carolina. There was a general storm surge presentation given by the Science and Operations Officer at the NWS Newport/Morehead City WFO followed by a brief presentation by the survey administrator providing information related to the survey. There was a total of 24 eligible participants at the meeting with 23 survey respondents, including $15 \mathrm{ESFs}$ (nine of whom self-identified as EMs), four NWS forecasters, two media representatives, and two members of the public. The remaining five ESFs included two local or regional government officials, two transportation or school officials, and one public safety official. One person abstained from taking the survey because he believed he lacked the background and experience necessary to participate. The questions targeted current and potential future use of surge information from daily to seasonal time scales as well as formats and types of information that users desire. The survey was purposely vague in terms of individual characteristics such as age and job description to protect individual identity given the relatively small storm surge community in eastern North Carolina. All but one respondent answered all questions, but fewer responded to the open-ended questions at the end. The one individual seemed to have overlooked about one-quarter of the survey. Where appropriate, the number of total responses per finding is included in the results section.

Multiple choice questions, including a series of questions using the Likert scale, comprised 15 of the 22 questions in the survey. Results from these questions were calculated either by a straight frequency analysis or, in the case where the order of selection was important, a linearly weighted frequency analysis, with weights decreasing by selected response (i.e., a response of " $d a b c$ " would result in $d=4, a=3, b=2, c=1$ ). The remaining seven questions were free response. The responses to these questions were transcribed into an 
Excel worksheet by storm surge user with their selfselected category (i.e., EM) included to allow for comparison across questions and user group. About half of the information collected in the free response portion of this survey is related to the timing of storm surge information. This information, being quantitative in nature, was portrayed in two figures to provide a visualization of the data. The remaining qualitative portion of the free response was further compiled into themes for each question by user type. Themes were identified mainly through repetition of response and by user category, where themes were weighted toward the higher frequency of similar answers. However, the analysis attempted to be as inclusive as possible while preserving desired simplicity in terms of the overall message. This portion of the analysis was revisited by the authors to assure that no important information was left out and to also to avoid the potential for bias in this stage of the research. Research bias is expected to be minimal if any at all, with any small bias likely limited to how the survey was constructed. However, the ESF, EM, and, to a lesser extent, the NWS categories with larger sample sizes are likely more reliable than the media and public categories. As in any location, users of storm surge information in North Carolina may have biases that are regionally specific and related to local experience with the storm surge hazard characteristics (i.e., they receive surge from tropical and extratropical cyclones), influences from local geography, and related rules and policies.

\section{Results}

The survey results can be divided into four areas of concern, starting first with uses of storm surge information along with required and desired lead times. Attention then turns to the needs of these groups of users with respect to the information that would be most useful and the most appropriate formats of that information.

\section{a. Uses of storm surge information}

In response to a series of both multiple-choice and open-ended questions, ESFs, including EMs, identified that they use storm surge information to assess and communicate risk, to educate the public, to evacuate the public, or for long-term resilience and recovery planning. The NWS forecasters had similar responses for surge information use and how it affects their operations, stating that this information is part of the forecast process and is used for assessing and communicating surge risk to the public and to partners. The two media respondents use surge information to communicate threats to the public. The two public citizen respondents were most interested in information about evacuation and when they can return home.

\section{b. Lead times}

Sixteen respondents (89\%) first learned about a possible storm surge event between one and five days prior to the event with two-thirds citing between two and four days (Fig. 2). Fourteen ( $82 \%$ ) of the same respondents first learned of potential surge magnitude and timing with two days or less of lead time (Fig. 2). This finding suggests up to a 3-day margin between when respondents first learn of a potential surge event and when they become aware of the possible magnitude and timing.

Overall, storm surge event lead times of a week or less were most valued, although there was significant interest in the potential for longer lead times. Respondents were asked to provide the shortest and longest beneficial lead times of surge information, and how these lead times would facilitate related operations. The shortest lead time that would be beneficial to operations ranged from $12 \mathrm{~h}$ to 4 days, with one response stating one week (Fig. 3). According to multiple EM and ESF responses, the shortest lead times, not surprisingly, provide the most accurate information, aiding the best possible decision-making with just enough time to alert the public and mobilize resources. NWS forecasters stated that short lead times were beneficial in that these forecasts have the highest accuracy and probability for warning the public as well as planning for and communicating potential impacts. There were mixed results from the media and public citizen representatives, with lead times of around $48 \mathrm{~h}$ preferred by one of each of the two groups and up to two weeks for the remaining media and public representatives. One member of the media showed some dependence on EMs as that individual typically first learns of a potential surge event from their local EMs.

The longest lead times that would be beneficial to operations ranged from $12 \mathrm{~h}$ to a month or longer. Of those responses, over half ( 12 of 21 ; two respondents abstained) stated that a week or greater lead times would be beneficial to operations, despite being made aware that forecasts become less detailed as lead times increase. In fact, ESFs involved with evacuations ahead of a potential surge event identified either 1) learning about a surge event or 2) being interested in learning about surge events about four days to two weeks in advance. The longest lead times would benefit operations by providing additional time for planning and staging, thereby allowing for quicker recovery or return to normal operations following a significant or disruptive surge event. On the other hand, one ESF stated that she may 


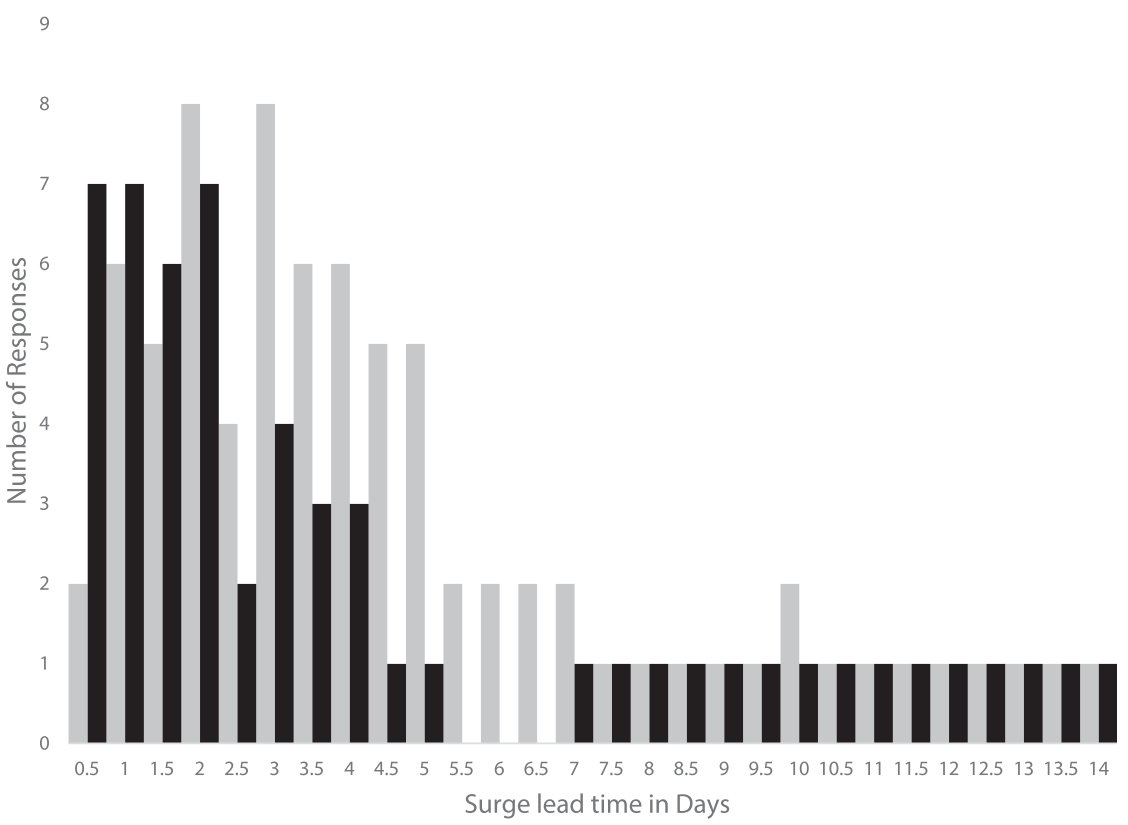

FIG. 2. Frequency statistics of the lead time each individual respondent first learned of a potential storm surge event (light gray) and the expected surge magnitude and timing (dark gray). Respondents were allowed to give a range of days.

use surge information at the longer lead times only for informational purposes and that it would not likely impact decision-making.

Although there is significant interest in, and in some cases a need for, longer lead times for storm surge, there are also concerns about the accuracy and meaning of this information. Several respondents were concerned about the potential for complacency given less accurate information or the potential for frequent changes. A similar response was noted from media respondents in Morrow and Lazo (2013). Another concern was that it may be confusing to some audiences. An NWS forecaster stated that "communicating threats during low probability, but high impact events seems to be most difficult." However, another NWS forecaster was more optimistic, stating that they had "no concerns, just need to educate on meaning and uses." An ESF thought that fisherman and farmers would find the longer lead times to be interesting, but that they would be unlikely to use it, similar to the El Niño-Southern Oscillation predictions. This person further stated that they often hear farmers and fisherman stating "I still have to take the chance to plant/fish" in spite of an unfavorable prediction. The same respondent also recommended learning the needs and preferences of other surge user groups such as homeowners and businesses to see if a 6-month forecast (for example) would make them more likely to seek a home elevation or other mitigation.

\section{c. Types of surge information}

Overall, the impacts of storm surge were a higher priority than the type of storm (tropical or extratropical), with 19 of 23 respondents selecting that option, similar to the findings of Lazo and Morrow (2013) in their survey of the public. Survey respondents were most interested in event-specific details, including the probability of moderate/strong surge events and length of a surge event. There was limited interest for how often surge events will likely occur over a given period of time,

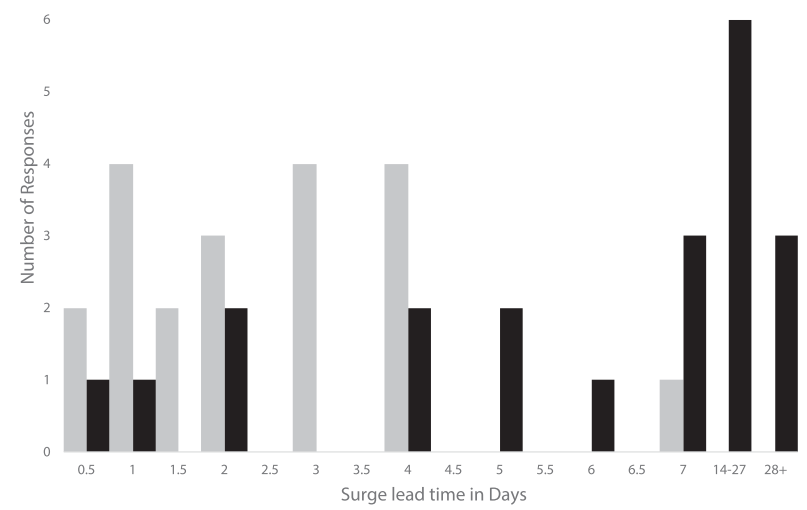

FIG. 3. Frequency statistics of the shortest (light gray) and longest (dark gray) lead times that would be beneficial to respondents' operations. 
TABLE 1. Averaged Likert response of different surge user groups when asked if each given surge variable had a significant impact on decision-making related to operations. EM is emergency managers, ESF is other emergency support functions, NWS is National Weather Service forecasters, and PC is public citizens.

\begin{tabular}{lcccccc}
\hline \hline & Height & Frequency & Duration & Start & End & Speed \\
\hline EM (9) & 4.1 & 4.1 & 4.7 & 4.7 & 4.8 & 4.8 \\
ESF (5) & 4.8 & 4.0 & 4.6 & 4.6 & 4.2 & 4.4 \\
NWS (4) & 5.0 & 3.3 & 5.0 & 4.8 & 4.5 & 4.3 \\
Media (2) & 5.0 & 3.5 & 5.0 & 5.0 & 5.0 & 5.0 \\
PC (2) & 5.0 & 4.5 & 5.0 & 5.0 & 5.0 & 5.0 \\
All (22) & 4.6 & 3.9 & 4.8 & 4.7 & 4.6 & 4.6 \\
\hline
\end{tabular}

for example if a particular season was forecast to be active or quiet. These results were investigated further through a Likert scale of 1 (disagree) to 5 (agree) in a series of six statements, related to whether surge height, duration, start time, end time, or speed of onset or frequency across a given month or season have a significant impact on decision-making related to operations. Table 1 breaks down the averaged Likert response by surge user group and surge variable. All surge specific characteristics were determined to be important by nearly all respondents with $91 \%$ or more of the respondent selecting either "agree somewhat" or "agree" and $68 \%$ or more selecting "agree." At the same time, storm surge frequency over a given month or season was found to have less of an impact on decision-making, with $64 \%$ of respondents selecting "agree somewhat" or "agree" and the remaining 36\% selecting "neutral." Interestingly, EMs noted that surge height (average Likert score 4.1) was less important than start time, end time, duration, and speed, which all had averages of 4.7 or 4.8 (Table 1). This could be related to EMs keeping public safety in mind as they are responsible for issuing evacuation orders and initiating recovery operations, which are, in turn, related to the timeline of flooding across the region and not necessarily to the magnitude of flooding, similar to the findings of Losego et al. (2012). However, height was deemed most important for NWS and ESF respondents, with average scores of 4.8 and 5.0 respectively. The NWS issues forecasts for water height above ground, and emergency responders need to know depth because they often put their safety at risk by going into flooded areas. On the other hand, the media and public representatives all selected "agree" for the usefulness of all types of storm surge information except for frequency (Table 1).

\section{d. Formats of surge information}

Question number 21 asked about preferred formats for a surge outlook, with four options: 1) climate outlooks providing simplified surge prediction similar to the
TABLE 2. User group preferred formats for receiving surge information. Options include climate outlooks (option A), surge probability and magnitude of surge by day (similar to weather forecasts; option B), and weekly briefing packets (option C). Abbreviations are as in Table 1 .

\begin{tabular}{lrrr}
\hline & A & B & C \\
\hline EM (9) & 4.0 & 5.0 & 5.0 \\
ESF (6) & 5.0 & 1.0 & 4.0 \\
NWS (4) & 3.0 & 3.0 & 2.0 \\
Media (2) & 1.0 & 1.0 & 1.0 \\
PC (2) & 0.0 & 2.0 & 0.0 \\
All (23) & 13.0 & 12.0 & 12.0 \\
\hline
\end{tabular}

Climate Prediction Center's rainfall and temperature products, 2) probability and magnitude by day (out to two weeks), more analogous to weather forecasts, 3) weekly briefings, and 4) other. There was nearly equal interest in all formats for respondents as a whole, as well as for EMs and NWS forecasters, with no respondent selecting the "other" option (Table 2). On the other hand, ESFs preferred climate outlooks and weekly briefing packets. The two private citizens preferred the probability and magnitude by day (out to two weeks), while two of the four NWS forecasters preferred all three options, with only three of the remaining 18 respondents selecting all three. Storm surge at the coast is complicated and ESFs seem to recognize the complexities, suggesting other important surge information or formats when asked to list additional information that would be useful to their operations. Examples include examining surge information using different forms of visualization such as on a Geographic Information System platform as well as incorporating inland rainfall and flooding as it relates to surge at the coast. The interest in and knowledge of surge within their area suggests they are seeking out or desire more surge information. The NWS Newport/Morehead City WFO has helped to foster this desire for surge information as evidenced by the Hurricane Conference and IWT meeting where this survey took place.

\section{Summary and conclusions}

This research has examined interests of specialized users of storm surge information regarding longer lead times of surge information as well as the type and format of surge information, including and beyond what is currently available.

The results from the survey show that surge users, mainly EMs, ESFs, and NWS forecasters, currently use surge information to assess and communicate surge risk, educate the public, and order evacuations, and for long-term resilience and recovery planning. Surge users as a whole were especially interested in additional types 
of surge information beyond surge height, including the duration, timing (including starting and ending times), and speed of surge onset. There was less interest in the frequency of surge at monthly to seasonal scales. The results also indicate that surge users would benefit from longer lead times of storm surge information. Storm surge users generally require surge information out to four days, but for about half of the respondents, surge information at lead times of a week or greater would benefit operations, which exceeds currently available storm surge lead times. This finding aligns with previous research stating that EMs and media (broadcast meteorologists) desire greater lead times, especially when it comes to evacuations (e.g., Losego et al. 2012; Morrow and Lazo 2013). Superstorm Sandy (2012) is a significant recent example of EMs needing accurate surge information at greater lead times as several EMs had to make critical evacuation decisions $72 \mathrm{~h}$ before landfall (e.g., Hoekstra and Montz 2017b).

There were significant concerns from several of the respondents related to the level of detail and accuracy of potential surge information at longer lead times. This suggests that caution should be taken during the developmental phases of extending the lead times of available surge information. This would help to ensure a balance between the detail and type of information and the associated accuracy of surge information at longer lead times that would provide utility to end users, while gaining their trust. An iterative process of testing the new surge information at longer lead times with surge users throughout the product development process will help to ensure the usefulness of the products in the future. Additionally, the involvement of surge users within the development process will help to facilitate learning about how and when the new surge products would be used and how to educate users on the potential utility and limitations of the surge information.

Weekly to seasonal surge forecasting, however, if accurate and dependable enough, may help to heighten awareness at these time scales. Potential benefits include 1) increasing awareness of at risk populations, with educational materials aimed at providing appropriate responses before, during, and after significant surge events, 2) increasing the response rate and preparedness for individual storms during the season, and 3) initiating protective actions for individual, commercial, and government entities. Thus, while surge information at longer lead times will likely be unreliable at times (similar to extended weather forecasts and climate outlooks), stronger or better-known surge relationships to weather and climate may assist in triggering important preparatory actions. Southern California offers a comparable example with the most recent, well-predicted, record-breaking
El Niño (2015/16) as local governments and individuals took preparative actions (i.e., clearing debris from riverbeds and repairing structures such as roofs) well in advance of what was expected to be an abnormally active rainy season.

\section{a. Study limitations}

Even though the total number of respondents was limited to 23, the strength of the survey is its regional focus on eastern North Carolina. This can also be a limitation of the study, however, as the results may not be transferrable to other coastal locations. Characteristics including geography and vulnerability to storm surge from different storm types as well as societal and policy characteristics will differ, but it would be interesting to reproduce the survey in other coastal regions to determine if the needs are universal or regionally specific.

The cross section of study participants had been invited to the meeting where the survey took place by the NWS Newport/Morehead City WFO and also included a few representatives from the WFO itself. While there was significant representation of EMs and other ESFs, the representation from the other three groups [NWS forecasters (4), media (2), and members of the public (2)] was limited due to a combination of the intent of the meeting and characteristics of the region.

\section{b. Recommendations}

The following tiered approach (closely mirroring currently available weather and climate prediction) might contribute to bringing current or near future numerical and climate prediction research to operations, thereby providing additional services to storm surge users.

1) For days $1-5$, detailed surge information with the probability of different magnitude surge events could be provided, matching the science to the needs of the customer [as recommended by Morss et al. (2011)]. In addition to surge height (or depth), this survey found that other surge information such as start and end times, duration, and how quickly the water advances inland has a significant impact on decisionmaking related to operations and could be incorporated as numerical modeling limitations allow.

2) Days 6-14 could be provided in the much desired climate format (i.e., two periods broken into days 6-9 and 10-14) with less detail, but possibly similar surge variables, as the science allows.

3) Beyond two weeks out to several months, monthly to seasonal outlooks could provide probabilities of given magnitudes or frequencies of storm surge to assist in longer-term planning and resource management.

There is increasing confidence that the science behind storm surge may be able to match the demand for 
user-desired longer lead times (e.g., Munroe and Curtis 2017). The results from this research should encourage investment of efforts in both continued development of surge products through a combination of numerical weather and climate prediction and surveys and other means to determine how to best provide this information to surge users.

Acknowledgments. The authors thank the Newport/ Morehead, North Carolina NWS WFO for supporting this research, including the distribution of the survey at their Hurricane Conference and IWT meeting. They would also like to thank the anonymous survey participants. Robert Munroe received funding through East Carolina University's Coastal Resource Management $\mathrm{Ph} . \mathrm{D}$. program during the preparation and data collection phases of this research.

\section{REFERENCES}

Bradford, R. A., and Coauthors, 2012: Risk perception-Issues for flood management in Europe. Nat. Hazards Earth Syst. Sci., 12, 2299-2309, https://doi.org/10.5194/nhess-12-2299-2012.

Carr, R. E., B. Montz, K. Semmens, K. Maxfield, S. Hoekstra, and E. Goldman, 2016: Motivating action under uncertain conditions: Enhancing emergency briefings during coastal storms. Wea. Climate Soc., 8, 421-434, https://doi.org/10.1175/WCASD-16-0028.1.

Catalano, A. J., and A. J. Broccoli, 2018: Synoptic characteristics of surge-producing extratropical cyclones along the northeast coast of the United States. J. Appl. Meteor. Climatol., 57, 171-184, https://doi.org/10.1175/JAMC-D-17-0123.1.

Dangendorf, S., T. Wahl, H. Hein, J. Jensen, S. Mai, and C. Mudersbach, 2012: Mean sea level variability and influence of the North Atlantic Oscillation on long-term trends in the German Bight. Water, 4, 170-195, https://doi.org/10.3390/w4010170.

DeGaetano, A., 2008: Predictability of seasonal east coast winter storm surge impacts with application to New York's Long Island. Meteor. Appl., 15, 231-242, https://doi.org/10.1002/met.59.

Demeritt, D., S. Nobert, H. Closea, and F. Papperberger, 2010: Challenges in communicating and using ensembles in operational flood forecasting. Meteor. Appl., 17, 209-222, https:// doi.org/10.1002/met.194.

Dillon, R. L., C. H. Tinsley, and M. Cronin, 2011: Why near-miss events can decrease an individual's protective responses to hurricanes. Risk Anal., 31, 440-449, https://doi.org/10.1111/ j.1539-6924.2010.01506.x.

Dolan, R., and R. Davis, 1994: Coastal storm hazards. J. Coast. Res., 12, 103-144.

Hoekstra, S., and B. Montz, 2017a: Decisions under duress: Factors influencing emergency management decision making during Superstorm Sandy. Nat. Hazards, 88, 453-471, https://doi.org/ 10.1007/s11069-017-2874-7.

$\longrightarrow$, and $-2017 \mathrm{~b}$ : The inside story: Timeline of events and communication leading up to Superstorm Sandy from the emergency manager perspective. Environ. Hazards, 16, 330344, https://doi.org/10.1080/17477891.2017.1301358.

Lazo, J., and B. Morrow, 2013: Survey of coastal U.S. Public's perspective on extra tropical-tropical cyclone storm surge information. NCAR Societal Impacts Program, 109 pp., http:// www.sip.ucar.edu/projects/stormsurge/2013_01_07_ETTC_ Storm_Surge_Public_Survey_Report.pdf.

Lindell, M. K., and R. W. Perry, 2012: The protective action decision model: Theoretical modifications and additional evidence. Risk Anal., 32, 616-632, https://doi.org/10.1111/ j.1539-6924.2011.01647.x.

Losego, L., K. Galluppi, B. Montz, C. Smith, and S. Schotz, 2012: Weather for emergency management: Implications for NWS tropical weather products and services. Seventh Symp. on Policy and Socio-Economic Research, New Orleans, LA, Amer. Meteor. Soc., 8A.3, https://ams.confex.com/ams/ 92Annual/webprogram/Paper197676.html.

Meyer, R., J. Baker, K. Broad, J. Czajkowski, and B. Orlove, 2014: The dynamics of hurricane risk perception: Real-time evidence from the 2012 Atlantic hurricane season. Bull. Amer. Meteor. Soc., 95, 1389-1404, https://doi.org/10.1175/BAMS-D-12-00218.1.

Morrow, B., and J. Lazo, 2013: Broadcast media on-line survey on extratropical and tropical cyclone forecast information: NOAA Storm Surge Roadmap and hurricane forecast improvement program. NCAR Tech. Note NCAR/TN498+STR, 83 pp., doi:10.5065/D69P2ZM1.

,$- \ldots$, J. Rhome, and J. Feyen, 2015: Improving storm surge risk communication: Stakeholder perspectives. Bull. Amer. Meteor. Soc., 96, 35-48, https://doi.org/10.1175/BAMS-D-13-00197.1.

Morss, R. E., J. K. Lazo, and J. L. Demuth, 2010: Examining the use of weather forecasts in decision scenarios: Results from a US survey with implications for uncertainty communication. Meteor. Appl., 17, 149-162, https://doi.org/10.1002/met.196.

—, O. V. Wilhelmi, G. A. Meehl, and L. Dilling, 2011: Improving societal outcomes of extreme weather in a changing climate: An integrated perspective. Annu. Rev. Environ. Resour., 36, 1-25, https://doi.org/10.1146/annurev-environ-060809-100145.

Munroe, R., and S. Curtis, 2017: Storm surge evolution and its relationship to climate oscillations at Duck, NC. Theor. Appl. Climatol., 129, 185-200, https://doi.org/10.1007/s00704-016-1770-5.

NOAA, 2017: Storm surge watch \& warning to become operational in 2017. NOAA, 2 pp., http://www.nhc.noaa.gov/news/ 20170123_pa_SSWW.pdf.

Rappaport, E. N., 2014: Fatalities in the United States from Atlantic tropical cyclones: New data and interpretation. Bull. Amer. Meteor. Soc., 95, 341-346, https://doi.org/10.1175/BAMSD-12-00074.1.

Sweet, W. V., and C. Zervas, 2011: Cool-season sea level anomalies and storm surges along the U.S. East Coast: Climatology and comparison with the 2009/10 El Niño. Mon. Wea. Rev., 139, 2290-2299, https://doi.org/10.1175/MWR-D-10-05043.1.

Thompson, P., G. Mitchum, C. Vonesch, and J. Li, 2013: Variability of winter storminess in the eastern United States during the twentieth century from tide gauges. J. Climate, 26, 9713-9726, https://doi.org/10.1175/JCLI-D-12-00561.1.

Wakelin, S., P. L. Woodworth, A. Flather, and J. A. Williams, 2003: Sea-level dependence on the NAO over the NW European continental shelf. Geophys. Res. Lett., 30, 1403, https://doi.org/ 10.1029/2003GL017041.

Wood, M. M., D. S. Mileti, M. Kano, M. M. Kelley, R. Regan, and L. B. Bourque, 2012: Communicating actionable risk for terrorism and other hazards. Risk Anal., 32, 601-615, https:// doi.org/10.1111/j.1539-6924.2011.01645.x.

Zhang, K., B. Douglas, and S. Leatherman, 2000: Twentieth-century storm activity along the U.S. East Coast. J. Climate, 13, 1748-1761, https://doi.org/10.1175/1520-0442(2000)013<1748: TCSAAT $>2.0 . \mathrm{CO} ; 2$. 